\title{
Sistem Pendukung Keputusan Penentuan Tingkat Kecanduan Masyarakat Terhadap Rokok dengan Metode Fuzzy Mamdani
}

\author{
Daniel Andre Marpaung ${ }^{1 *}$, Murni Marbun² \\ ${ }^{1,2}$ STMIK Pelita Nusantara \\ Jl. Iskandar Muda No. 1 Medan 20154 Indonesia \\ Corresponding author's e-mail: danielmarpaung62@gmail.com
}

\begin{abstract}
Abstrak - Kecanduan seseorang terhadap rokok dapat dilihat dari ciri-ciri pecandu rokok tersebut antara lain: susah mengendalikan keinginan untuk merokok, nafsu makan tinggi, sering batuk, gangguan tidur, dan susah untuk berkonsentrasi. Kecanduan seseorang terhadap rokok dapat membawa dampak yang buruk bagi bagi kesehatan orang tersebut. Penelitian menggunakan metode Fuzzy Mamdani. Sistem dibangun dengan menggunakan bahasa pemrograman Hypertext Preprocessor (PHP). Sistem manajemen basis data menggunakan My Structured Query Language (MYSQL). Kriteria-kriteria tingkat kecanduan masyarakat terhadap rokok yaitu biaya, frekuensi merokok, dan lingkungan. Penelitian bertujuan merancang Sistem Pendukung Keputusan penentuan tingkat kecanduan masyarakat terhadap rokok dan menerapkan metode Fuzzy Mamdani untuk penentuan tingkat kecanduan masyarakat terhadap rokok. Maka dapat disimpulkan bahwa tingkat kecanduan orang tersebut berada pada angka 13 atau dikategorikan sebagai CANDU.

Kata kunci: Fuzzy, fungsi keanggotaan, rule, metode Mamdani
\end{abstract}

Abstract - A person's addiction to smoking can be seen from the characteristics of the cigarette addict, including: difficulty controlling the desire to smoke, high appetite, frequent coughing, sleep disturbances, and difficulty concentrating. A person's addiction to cigarettes can have a bad impact on the health of that person. The research used the Fuzzy Mamdani method. The system was built using the Hypertext Preprocessor (PHP) programming language. The database management system uses My Structured Query Language (MYSQL). The criteria for the level of community addiction to cigarettes are cost, smoking frequency, and the environment. This study aims to design a Decision Support System for determining the level of community addiction to smoking and applying the Fuzzy Mamdani method for determining the level of community addiction to cigarettes. So it can be concluded that the person's level of addiction is at number 13 or categorized as CANDU.

Keywords: Fuzzy, membership function, rule, Mamdani method

\section{Pendahuluan}

Rokok adalah produk yang berasal dari olahan tembakau yang digulung dan dibungkus dengan kertas dengan panjang 8-10 cm. Bahaya rokok sudah banyak diketahui oleh masyarakat, namun tetap saja masih banyak orang yang melakukan kegiatan merokok. Rokok merupakan produk yang mengandung zat-zat berbahaya bagi tubuh manusia. Salah satu zat yang berbahaya yang terdapat dalam rokok adalah zat adiktif yang dapat menyebabkan kecanduan bagi perokok tersebut. Kecanduan seseorang terhadap rokok disebabkan oleh kandungan nikotin yang terdapat didalam rokok. Nikotin merupakan zat yang menyebabkan adiksi (ketagihan) dengan toleransi tinggi, yaitu semakin banyak dikonsumsi maka semakin bertambah tingkat kecanduannya. Beberapa hal yang mendorong masyarakat untuk melakukan kegiatan merokok antara lain yaitu, coba-coba, ikut-ikutan, pelarian dari rasa frustasi, agar terlihat keren, mencari inspirasi dan lain-lain.

Penelitian berjudul Analisis Fuzzy Logic Menentukan Pemilihan Motor Honda Dengan Metode Mamdani. PT Indoprof Motor Sejati merupakan perusahaan dealer motor di Tanjung Uban. Dalam melakukan kegiatannya, PT Indoprof Motor Sejati perlu mempertimbangkan beberapa faktor pada saat melakukan pembelian motor [1].

Penelitian berjudul Penerapan Metode Fuzzy Mamdani Untuk Memprediksi Jumlah Produksi Karet (Studi Kasus: Data Persediaan Dan Permintaan Produksi Karet Pada PTP Nusantara XIV (Persero) Kebun Awaya, Teluk Elpaputih, Maluku-Indonesia). Dalam memproduksi diperlukan perencanaan produksi yang tepat. Penelitian ini menggunakan data dari PTP Nusantara XIV (Persero) Kebun Awaya/Teluk Elpaputih, yang bergerak dalam bidang produksi karet mentah. Penelitian ini menggunakan metode Fuzzy Mamdani untuk meramalkan jumlah produksi karet berdasarkan data permintaan, persediaan dan produksi karet per hari pada bulan April 2016 [2]. Sistem pendukung keputusan (SPK) biasanya dibangun untuk mendukung solusi 
atas suatu masalah atau untuk mengevaluasi suatu peluang atau sering juga disebut sebagai aplikasi SPK [3]. Aplikasi SPK biasanya menggunakan CBIS (Computer Based Information System) yang fleksibel, interaktif, dan dapat diadaptasi, yang dikembangkan untuk mendukung solusi atas masalah manajemen spesifik yang tidak terstruktur. Salah satu metode yang digunakan untuk sistem pengambilan keputusan adalah Logika Fuzzy [4].

Logika Fuzzy merupakan teknik/ metode yang dipakai untuk mengatasi hal yang tidak pasti pada masalahmasalah yang mempunyai banyak jawaban. Pada dasarnya Fuzzy logic merupakan logika bernilai banyak/ multivalued logic yang mampu mendefinisikan nilai diantara keadaan yang konvensional seperti benar atau salah, ya atau tidak, putih atau hitam dan lain-lain [5]. Penalaran Logika Fuzzy menyediakan cara untuk memahami kinerja system dengan cara menilai input dan output system dari hasil pengamatan. Logika Fuzzy menyediakan cara untuk menggambarkan kesimpulan pasti dari informasi yang samar-samar, ambigu dan tidak tepat. Pemecahan masalah dalam Logika Fuzzy dapat dilakukan dengan beberapa metode, salah satunya adalah metode Fuzzy Mamdani [6].

Metode Fuzzy Mamdani merupakan salah satu bagian dari Fuzzy Inference System yang berguna untuk penarikan kesimpulan atau suatu keputusan terbaik dalam permasalahan yang tidak pasti [7]. Metode Fuzzy Mamdani dalam prosesnya menggunakan kaedah-kaedah linguistik dan memiliki algoritma fuzzy yang dapat dianalisis secara matematika, sehingga lebih mudah dipahami. Proses pengambilan keputusan dengan menggunakan Metode Fuzzy Mamdani untuk memperoleh keputusan yang terbaik, dilakukan dengan melalui beberapa tahapan, yaitu pembentukan himpunan fuzzy, aplikasi fungsi implikasi, komposisi aturan, dan defuzzifikasi [8].

\section{Tinjauan Pustaka}

\subsection{Logika Fuzzy}

Logika fuzzy adalah metodologi system control pemecahan masalah, yang cocok untuk diimplementasikan pada sistem, mulai dari sistem yang sederhana, sistem kecil, embedded system, jaringan PC, multichannel atau workstation berbasis akuisisi data, dan sistem control. Logika fuzzy merupakan logika yang memiliki nilai kekaburan atau kesamaran (fuzziness) antara benar atau salah [9]. Dalam logika fuzzy nilai bisa bernilai benar dan salah secara bersamaan, namun berapa besar nilainya tergantung pada bobot keanggotaan yang dimilikinya. Logika fuzzy memiliki beberapa komponen yang harus dipahami seperti himpunan fuzzy, fungsi keanggotaan, operator pada himpunan fuzzy, fungsi implikasi, inferensi fuzzy dan defuzzifikasi.

\subsection{Metode Mamdani}

Metode Mamdani paling sering digunakan dalam aplikasi-aplikasi karena strukturnya yang sederhana, yaitu menggunakan operasi MIN-MAX atau MAX-PRODUCT [10]. Untuk mendapatkan output, diperlukan 4 tahapan yaitu :

1. Fuzzyfikasi (pembentukan himpunan fuzzy)

Pada Metode Mamdani, baik variabel input maupun variabel output dibagi menjadi satu atau lebih himpunan fuzzy.

2. Aplikasi fungsi implikasi

Pada metode Mamdani, fungsi implikasi yang digunakan adalah Min.

3. Komposisi Aturan

Apabila sistem terdiri dari beberapa aturan, maka inferensi diperoleh dari gabungan antar aturan. Ada tiga metode yang digunakan dalam melakukan inferensi sistem fuzzy, yaitu: max, additive dan probabilistik OR (probor).

a. Metode Max (Maximum)

Pada metode ini, solusi himpunan fuzzy diperoleh dengan cara mengambil nilai maksimum aturan, kemudian enggunakannya untuk memodifikasi daerah fuzzy, dan mengaplikasikannya ke output dengan menggunakan operator OR (union). Jika semua proposisi telah dievaluasi, maka output akan berisi suatu himpunan fuzzy yang merefleksikan konstribusi dari tiap-tiap proposisi.

b. Metode Additive (Sum)

Pada metode ini, solusi himpunan fuzzy diperoleh dengan cara melakukan bounded-sum terhadap semua output daerah fuzzy. Secara umum dituliskan :Usf [xi] = min (1, Usf [xi] + Ukf [xi])

c. Metode Probabilistik OR (probor)

Pada metode ini, solusi himpunan fuzzy diperoleh dengan cara melakukan product terhadap semua output daerah fuzzy. Secara umum dituliskan : Usf [xi] $=($ Usf [xi] + Ukf [xi] $-($ Usf [xi] . Ukf [xi]))

d. Penegasan (Defuzzifikasi)

Masukan dari proses defuzzifikasi adalah suatu himpunan fuzzy yang diperoleh dari suatu komposisi aturan- 
aturan fuzzy, sedangkan output yang dihasilkan merupakan suatu bilangan pada himpunan fuzzy tersebut. Sehingga diberikan suatu himpunan fuzzy dalam range tertentu, maka harus dapat diambil suatu nilai crisp tertentu sebagai output.

\section{Metode Penelitian}

Kerangka kerja penelitian merupakan langkah-langkah yang akan dilakukan dalam penyelesaian masalah yang akan dibahas. Adapun kerangka kerja penelitian, Gambar 1.

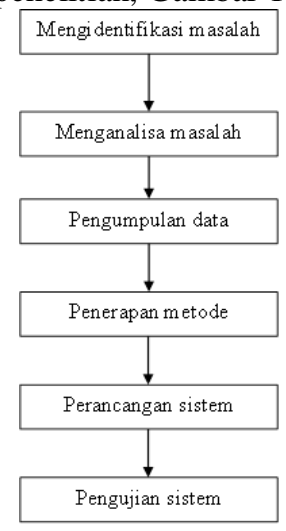

\section{Hasil dan Pembahasan}

Gambar 1. Metode Penelitian

Tahap pertama dari proses penyelesaian masalah dengan metode fuzzy adalah pembentukan himpunan fuzzy atau biasa disebut fuzzifikasi. Variabel yang digunakan dalam penentuan tingkat kecanduan mahasiswa terhadap rokok adalah Frekuensi, Biaya, dan Lingkungan sebagai variabel input dan Tingkat Kecanduan sebagai variabel output.penjelasan yang jelas sehingga pembaca dapat memahami isi dari hasil penelitian.

Tabel 1. Himpunan Fuzzy

\begin{tabular}{|c|c|c|c|c|}
\hline Fungsi & Variabel & Himpunan & Semesta & Domain \\
\hline \multirow[t]{9}{*}{ Input } & Frekuensi & Kadang & {$[0-25]$} & {$\left[\begin{array}{llll}0 & 5 & 10\end{array}\right]$} \\
\hline & & Sering & {$[0-25]$} & {$\left[\begin{array}{llll}5 & 10 & 15\end{array}\right]$} \\
\hline & & Sangat sering & {$[0-25]$} & {$\left[\begin{array}{lll}10 & 15 & 25\end{array}\right]$} \\
\hline & Biaya & Rendah & {$[0-25]$} & {$\left[\begin{array}{lll}0 & 5 & 10\end{array}\right]$} \\
\hline & & Sedang & {$[0-25]$} & {$\left[\begin{array}{lll}5 & 10 & 15\end{array}\right]$} \\
\hline & & Tinggi & {$[0-25]$} & {$\left[\begin{array}{lll}10 & 15 & 25\end{array}\right]$} \\
\hline & Lingkungan & Sedikit & {$[0-25]$} & {$\left[\begin{array}{lll}0 & 5 & 10\end{array}\right]$} \\
\hline & & Sedang & {$[0-25]$} & {$\left[\begin{array}{llll}5 & 10 & 15\end{array}\right]$} \\
\hline & & Banyak & {$[0-25]$} & {$\left[\begin{array}{llll}10 & 15 & 25\end{array}\right]$} \\
\hline \multirow[t]{3}{*}{ Output } & Kecanduan & Tidak Candu & {$[0-25]$} & {$\left[\begin{array}{lll}0 & 5 & 10\end{array}\right]$} \\
\hline & & Candu & {$[0-25]$} & {$\left[\begin{array}{llll}5 & 10 & 15\end{array}\right]$} \\
\hline & & Sangat candu & {$[0-25]$} & {$\left[\begin{array}{llll}10 & 15 & 25\end{array}\right]$} \\
\hline
\end{tabular}

Fungsi keanggotaan, Gambar 2.

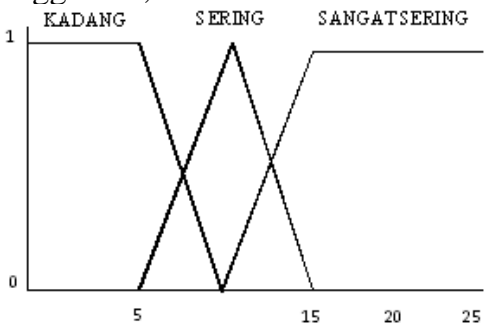

Fungsi Keanggotaan Frekuensi

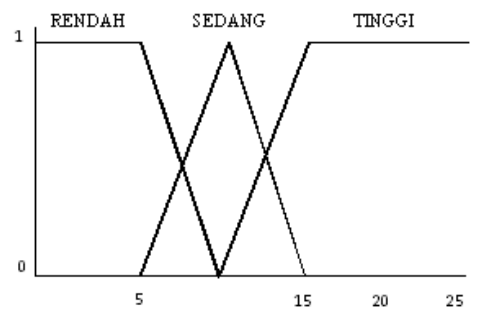

Fungsi Keanggotaan Biaya 


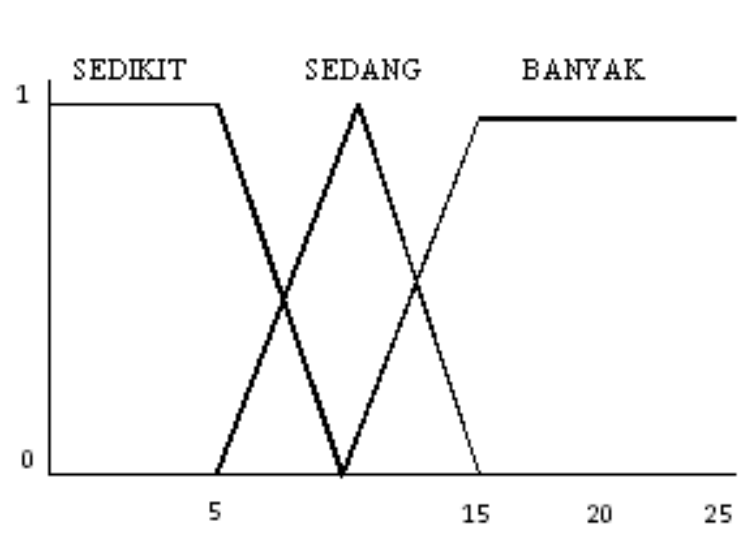

Fungsi Keanggotaan Lingkungan

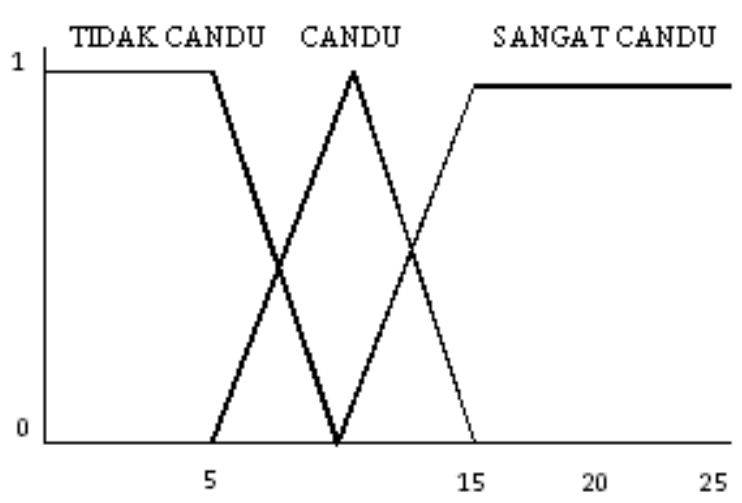

Fungsi Keanggotaan Kecanduan

Gambar 2. Fungsi Keanggotaan

Setelah pembentukan himpunan fuzzy, langkah selanjutnya adalah membentuk aturan fuzzy. [R1] : Jika frekuensi KADANG dan biaya RENDAH dan lingkungan SEDIKIT, maka keputusan TIDAK CANDU [R2] : Jika frekuensi KADANG dan biaya RENDAH dan lingkungan SEDANG, maka keputusan TIDAK CANDU

[R3] : Jika frekuensi KADANG dan biaya RENDAH dan lingkungan BANYAK, maka keputusan TIDAK CANDU

[R4] : Jika frekuensi KADANG dan biaya SEDANG dan lingkungan SEDIKIT, maka keputusan TIDAK CANDU

[R5] : Jika frekuensi KADANG dan biaya SEDANG dan lingkungan SEDANG, maka keputusan TIDAK CANDU

[R6] : Jika frekuensi KADANG dan biaya SEDANG dan lingkungan BANYAK, maka keputusan TIDAK CANDU

[R7] : Jika frekuensi KADANG dan biaya TINGGI dan lingkungan SEDIKIT, maka keputusan CANDU [R8] : Jika frekuensi KADANG dan biaya TINGGI dan lingkungan SEDANG, maka keputusan CANDU [R9] : Jika frekuensi KADANG dan biaya TINGGI dan lingkungan BANYAK, maka keputusan CANDU [R10] : Jika frekuensi SERING dan biaya RENDAH dan lingkungan SEDIKIT, maka keputusan TIDAK CANDU

[R11] : Jika frekuensi SERING dan biaya RENDAH dan lingkungan SEDANG, maka keputusan TIDAK CANDU

[R12] : Jika frekuensi SERING dan biaya RENDAH dan lingkungan BANYAK, maka keputusan TIDAK CANDU

[R13] : Jika frekuensi SERING dan biaya SEDANG dan lingkungan SEDIKIT, maka keputusan CANDU [R14] : Jika frekuensi SERING dan biaya SEDANG dan lingkungan SEDANG, maka keputusan CANDU [R15] : Jika frekuensi SERING dan biaya SEDANG dan lingkungan BANYAK, maka keputusan CANDU [R16] : Jika frekuensi SERING dan biaya TINGGI dan lingkungan SEDIKIT, maka keputusan SANGAT CANDU

[R17] : Jika frekuensi SERING dan biaya TINGGI dan lingkungan SEDANG, maka keputusan SANGAT CANDU

[R18] : Jika frekuensi SERING dan biaya TINGGI dan lingkungan BANYAK, maka keputusan SANGAT CANDU

[R19] : Jika frekuensi SANGAT SERING dan biaya RENDAH dan lingkungan SEDIKIT, maka keputusan CANDU

[R20] : Jika frekuensi SANGAT SERING dan biaya RENDAH dan lingkungan SEDANG, maka keputusan CANDU

[R21] : Jika frekuensi SANGAT SERING dan biaya RENDAH dan lingkungan BANYAK, maka keputusan CANDU

[R22] : Jika frekuensi SANGAT SERING dan biaya SEDANG dan lingkungan SEDIKIT, maka keputusan SANGAT CANDU

[R23] : Jika frekuensi SANGAT SERING dan biaya SEDANG dan lingkungan SEDANG, maka keputusan SANGAT CANDU 
[R24] : Jika frekuensi SANGAT SERING dan biaya SEDANG dan lingkungan BANYAK, maka keputusan SANGAT CANDU

[R25] : Jika frekuensi SANGAT SERING dan biaya TINGGI dan lingkungan SEDIKIT, maka keputusan SANGAT CANDU

[R26] : Jika frekuensi SANGAT SERING dan biaya TINGGI dan lingkungan SEDANG, maka keputusan SANGAT CANDU

[R27] : Jika frekuensi SANGAT SERING dan biaya TINGGI dan lingkungan BANYAK, maka keputusan SANGAT CANDU

Setelah aturan dibentuk, maka dilakukan aplikasi fungsi implikasi. Pada Metode Mamdani, fungsi implikasi yang digunakan adalah MIN, yang berarti tingkat keanggotaan yang didapat sebagai konsekuen dari proses ini adalah nilai minimum dari variabel frekuensi, biaya dan lingkungan. Sehingga didapatkan daerah fuzzy pada variabel keputusan untuk masing - masing aturan.

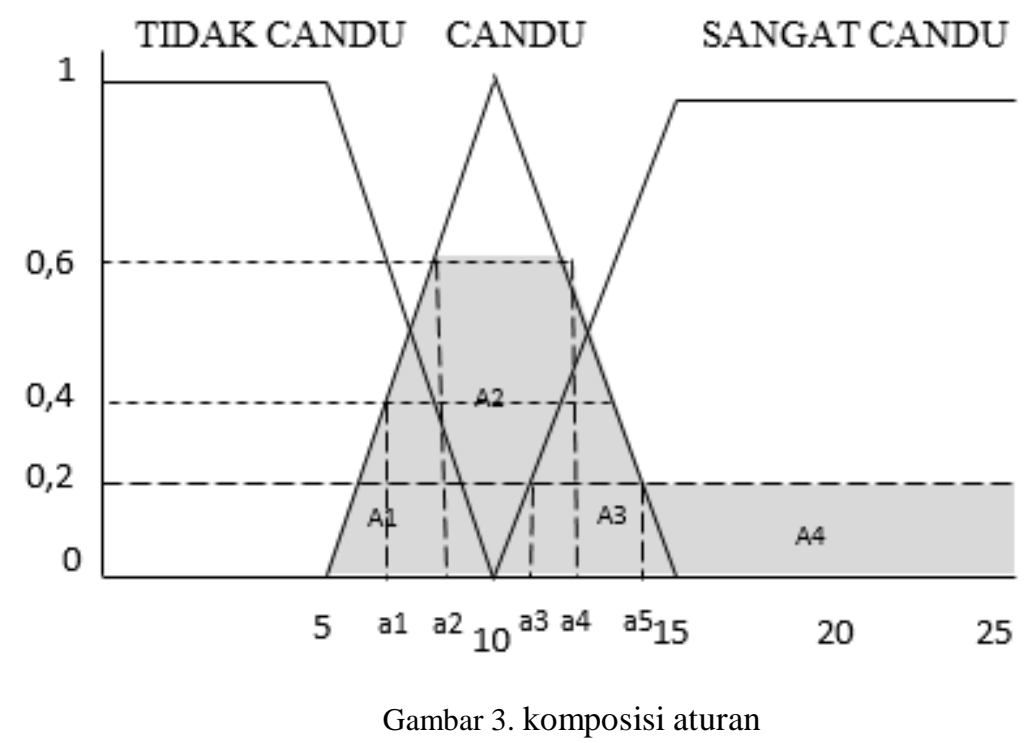

Berdasarkan gambar diatas maka langkah selanjutnya adalah menentukan nilai a1, a2 dan a3.

$(\mathrm{a} 1-5) / 5=0,4 \rightarrow$ a1 $=7$

$(\mathrm{a} 2-5) / 5=0,6 \rightarrow \mathrm{a} 2=8$

$(\mathrm{a} 3-10) / 5=0,2 \rightarrow \mathrm{a} 3=11$

$(\mathrm{a} 4-10) / 5=0,6 \rightarrow \mathrm{a} 4=13$

$(15-\mathrm{a} 5) / 5=0,2 \rightarrow$ a5 $=14$

Defuzzifikasi, metode penegasan yang digunakan adalah metode centroid. Maka, yang pertama adalah menghitung momen setiap daerah.

$\mathrm{Z}=\frac{\int_{5}^{8} \frac{z-5}{5} \mathrm{zdz}+\int_{8}^{13} 0,6 z d z+\int_{13}^{14} \frac{z-10}{5} \mathrm{zdz}+\int_{14}^{25} 0,2 \mathrm{zdz}}{\int_{5}^{8} \frac{z-5}{5} \mathrm{dz}+\int_{8}^{13} 0,6 d z+\int_{13}^{14} \frac{z-10}{5} \mathrm{dz}+\int_{14}^{25} 0,2 \mathrm{dz}}$

$\mathrm{Z}=\frac{6,3+31,5+9,46+42,9}{0,9+3+0,7+2,2} \mathrm{Z}=\frac{90,16}{6,8} \mathrm{Z}=13,258$

Maka dapat disimpulkan bahwa tingkat kecanduan orang tersebut berada pada angka 13 atau dikategorikan sebagai CANDU.

\section{Kesimpulan}

Kesimpulan dari penelitian :

1. Sistem pendukung keputusan dapat diterapkan dalam membangun sistem untuk mengidentifikasi tingkat kecanduan masyarakat terhadap rokok dengan menggunakan metode fuzzy mamdani.

2. Penerapan metode fuzzy mamdani dalam penentuan tingkat kecanduan masyarakat terhadap rokok memberikan hasil yang akurat sesuai jawaban dari kuesioner yang di isi oleh masing-masing responden.dilanjutkan.

6. Daftar Pustaka

[1] W. Buana, "Penerapan Fuzzy Mamdani Untuk Sistem Pendukung Keputusan Pemilihan Telepon 
Seluler," J. Edik Inform., vol. 2, pp. 138-143, 2014.

[2] M. Kastina and M. Silalahi, "Logika Fuzzy Metode Mamdani Dalam Sistem Keputusan Fuzzy Produksi Menggunakan Matlab,” J. Ilmu Komput., vol. 1, no. 2, pp. 171-181, 2016.

[3] A. Manan, V. Wiley, and T. Lucas, "Programmer Selection Using Modified Fuzzy Mamdani Method," Lontar Komput. J. Ilm. Teknol. Inf., vol. 10, no. 2, p. 108, 2019, doi: 10.24843/lkjiti.2019.v10.i02.p05.

[4] F. W. A. Much, Djunaidi, Eko Setiawan, "Penentuan Jumlah Produksi Dengan Aplikasi Metode Fuzzy-Mamdani,” J. Ilm. Tek. Insudtri, vol. 4, no. 2, pp. 95-104, 2005.

[5] R. Nazli et al., "KEPUTUSAN PENENTUAN GOLONGAN OBAT SESUAI DENGAN," vol. 1, no. 2, pp. 67-74, 2018.

[6] A. S. Sinaga and P. Marpaung, "EKSTRAK CIRI KOMUNIKASI NONVERBAL MENGGUNAKAN GRAY LEVEL CO-OCCURRENCE MATRIX,” vol. 12, no. 2, pp. 43-49, 2020.

[7] A. Sitio and A. S. R. Sinaga, "PEMANFAAATAN IT DALAM PELAKSANAAN UJIAN BERBASIS KOMPUTER PADA SMA NEGERI 2 PERBAUNGAN,” vol. 1, no. 1, pp. 1-9, 2020.

[8] P. Soepomo, "Implementasi Keam Anan Data Menggunakan," Simetris, vol. 2, no. 2252-4983, pp. 140-150, 2014.

[9] A. Sukoco and R. Yuli Endra, "Penerapan Fuzzy Inference System Metode Mamdani Untuk Pemilihan Jurusan,” J. Manaj. Sist. Inf. dan Teknol., pp. 89-99, 2016.

[10] A. S. RM. Sinaga, "Binary Image Object Identification Using Fuzzy Logic and Labeling BreadhFirst," Journal of Telematics and Informatics, vol. 6, no. 4, 2018. 